\title{
eJobs: Developing a Year-Round Electronic Job Placement Service
}

When hearing the name "Annual Meeting Placement Service," many former participants envision a vast hall filled with job candidates and employers anxiously flipping through binders looking for the perfect match. Those who attended the 2000 APSA meeting, would not have recognized the scene: a virtually empty bank of computers for searching jobs and a bustling interview area with candidates waiting to be called by departmental representatives. Development of an online job system has remade the anual Placement Service, with a paperless system evolving and participants doing the bulk of their searching before arrival at the meeting.

As one of its many online initiatives, APSA launched eJobs to simplify the job search and to improve the way qualified applicants are matched with open positions in political science. Both job candidates and employers registered for the service as much as three months in advance, enabling both to use a searchable database of candidate and job information. Over 800 job candidates took advantage of the service in 2000 , viewing nearly 500 available jobs. Many took advantage of the time to set up numerous interviews before the meeting, with some participants traveling for on-campus interviews prior to the Washington meeting.

The 2000 meeting marked the second year for the new system and the second generation of eJobs featured a number of enhancements over the previous version. Primary among these was an electronic message center that allowed employers and candidates to communicate via computer centers in any of the three primary meeting hotels. Among the new online features

was an improved search capability that allowed for more narrow searches on subfields and keywords.

The online system is not simply designed for the June-September placement season, though. APSA is expanding the service to create a yearround placement center that builds upon the online version of the Personnel Service Newsletter, the most comprehensive listing of jobs in political science. The year-round service will allow job candidates to post their resumes in a searchable database, making their complete employment and scholarly information available to potential employers.

Candidates may choose to have their information remain available for up to a year, and can edit their listing at any time. Visit the eJobs system (www. apsanet.org/ejobs) to learn more about year-round placement.

Ejobs will continue to evolve, making it the most advanced online system for finding jobs in political science. Perceptions of the Annual Meeting Job Placement Service will also evolve as job candidates and employers alike master a more flexible system, easing the tension of the placement process, and allowing for more attendance of meeting panels. Suggestions for improving the system are always welcome at ejobs@apsanet.org.

\section{APSA Directories Online}

The 2000-01 Directory of Department Chairs is now available online to individual and departmental services members. The directory contains listings for nearly 1300 colleges and universities that offer four-year degrees in political or social science. The directory is searchable by state, institution name, and chair name. Listings also include department name, address, phone and fax, chair email, department web site, department type, and Pi Sigma Alpha information. And coming in summer 2001: a members-only, web-based directory of email addresses for individual members! 